\title{
Peirce, para bem ou para mal, para além de Descartes
}

\author{
Renato Rodrigues Kinoughi
}

\section{O método anticartesiano de C. S. Peirce}

Lucia Santaella

Editora Unesp/Fapesp,

São Paulo, 2004, 277 págs.

Um dos traços marcantes da filosofia de Charles Sanders Peirce (1839-1914) foi sua preocupação com a constituição de uma comunidade intelectual. Isso porque, para o pragmatista, a ciência não se ergue sobre contribuições individuais, mas se estabelece no intercurso das experiências entre as pessoas que coletivamente promovem a expansão do conhecimento científico. Tais experiências "devem ser algo que afeta, ou que deveria afetar, a todos os homens. E embora essas afecções sejam necessariamente tão variadas quanto são as condições individuais, todavia o método [científico] deve ser um, tal que as conclusões finais de todos os homem sejam as mesmas" (Peirce, 1992, p. 120). Em outras palavras, independentemente de como as circunstâncias individuais condicionam as experiências de cada cientista, faz-se necessário algum consenso intersubjetivo sobre o mundo. É nesse sentido que devemos interpretar a afirmação pragmatista de que a verdade consiste na opinião final dos especialistas, quando se permite que a investigação se prolongue o suficiente. Não que aquilo que os especialistas dizem por ora tenha que ser tomado como a "palavra final", mas sim que os especialistas, ao investigar diligentemente, deveriam ser compulsoriamente levados ao consenso do que é real. Não haveria produção de conhecimento científico senão através do intercurso dessas ações e reações de uma comunidade de pesquisadores.

Mas essas colocações levantam algumas questões acerca da viabilidade do estabelecimento de fato de tal comunidade. Podemos sim imaginar uma comunidade ideal formada por pessoas honestamente devotadas à investigação, a despeito de suas inclinações e motivações pessoais. Mas certamente esse "céu na terra" não se deu. Por estarmos lidando com uma população, os cientistas podem ser considerados, "na média”, como sendo honestamente devotados à investigação. Todavia, fazer vista grossa com relação aos interesses individuais e corporativos que, para bem ou para mal, efetivamente influenciam os programas de pesquisa, seria uma flagrante ingenuidade. 
Em alguma medida, Peirce, tomado como indivíduo, foi uma vítima dessas circunstâncias que maculam aquele ideal de comunidade intelectual. Em vida ele sofreu diversos reveses que, se não impediram sua carreira, tornaram-na bem atribulada. Não que Peirce não fosse uma pessoa aparentemente de difícil trato, meio extravagante e talvez um tanto intransigente com relação a seus ideais (e qual filósofo não o é um pouco?). Mas, de fato, a versão peirceana do pragmatismo, ou melhor, seu pragmaticismo, não encontrou a mesma receptividade das versões de William James ou de John Dewey. Fica, então, a impressão de que ele foi essencialmente um outsider, um estranho no ninho. Isso, entretanto, é meia verdade, pois ele foi um pesquisador profissional que participava ativamente do debate filosófico-científico; muito embora não tenha alcançado a notoriedade que teria merecido, não foi um completo desconhecido. Digo isso para também não cair em uma idolatria do gênio incompreendido, um lugar comum no qual qualquer intelectual medíocre tem como se refugiar.

Tais circunstâncias biográficas, ao menos assim me parece, às vezes inclinam os mais aficcionados a imaginarem, com certo romantismo, a tal figura de um gaucher, banido da convivência com seus pares, que a todo custo buscou a verdade, de maneira honesta, conquanto extremamente solitária. Não obstante, a repetição desse mote talvez deprecie o verdadeiro espírito do filosofar de Peirce. O que se deveria sublinhar é que ele travava um intenso debate com os filósofos que o precederam. Estudos, por assim dizer, estritamente internalistas, perdem de vista o que há de mais importante em sua trajetória, a saber, seu lugar dentro da história da filosofia, e dentro mesmo da filosofia da ciência. Arrisco-me a dizer que, mais do que ser o fundador do pragmatismo, ou o pai da semiótica, ou o mais original pensador norte-americano, Peirce foi, antes de tudo, um notável filósofo da ciência; e isso é o que precisa ser dito ao público filosófico em geral.

Depois deste preâmbulo, posso agora assinalar o primeiro destaque ao livro de Lucia Santaella, cujo mérito consiste em colocar Peirce em diálogo com a história do pensamento, particularmente com o pensamento de René Descartes. Trata-se, então, de um estudo que não se exaure em temas circunscritos ao peircismo, mas, por assim dizer, transborda para além dessas fronteiras, o que garante o interesse de leitores de uma gama variada. Isso é possível porque a autora, que tem uma trajetória profunda e largamente consistente em semiótica, debruçou-se sobre temas gerais da história das idéias e dos métodos científicos. Nas palavras de Santaella: "Dessa necessidade [eu] já estava alerta por saber que o estudo dos métodos das ciências havia sido a única e grande paixão de Peirce, paixão que ele perseguiu pela vida afora" (p. 18). Em resumo, o Peirce apresentado é de natureza ampla, mostrado como pensador que não somente formulou um sistema de idéias, mas que também se articulava com outros sistemas. Posto isso, passemos agora a analisar mais de perto o conteúdo propriamente dito de O método anticartesiano de C. S. Peirce. 
O ponto de partida para se compreender os achados metodológicos de Peirce se encontra em sua crítica do conceito de intuição; conceito esse entendido como um tipo de cognição imediata, originária, sem auxílio de cognições anteriores, e disso derivam outras concepções tais como insight ou flash intuitivo. Segundo Santaella: "Peirce estava convencido de que não poderia haver nada mais inadequado e não confiável do que fundar o conhecimento na intuição, pois isso significa depositar, na consciência individual, a certeza do conhecimento e da investigação" (p. 47). Por sua vez, o filósofo pragmatista defendia que a aquisição de conhecimento consiste em uma cadeia de inferências, visando "evidenciar que cognições intuitivas, caso existam, não podem ser tomadas como sinônimos de certeza e infalibilidade" (p. 47). Com efeito, um dos mais eminentes filósofos que recorreram à intuição foi René Descartes, quando passa a adotar "como regra geral que todas as coisas que concebemos bastante clara e distintamente são verdadeiras" (Descartes, 1999 [1641] , p. 270). Mas note-se uma coisa da maior importância, qual seja, que Peirce combate o cartesianismo no que tange à fundamentação do conhecimento sobre a intuição; não obstante, não se pode dizer que ele se voltasse indiscriminada e levianamente contra o próprio Descartes. Na verdade, os dois também têm pontos em comum.

A primeira versão da máxima pragmática - qual seja, que para se apreender claramente uma idéia devemos considerar seus efeitos práticos e sensíveis sobre a experiência - encontra-se num artigo intitulado "How to make our ideas clear" (Peirce, 1992). Ora, nada poderia remeter mais a Descartes do que esse título e, como era de se esperar, aparecem críticas ao intuicionismo. Mas, logo em seguida, Peirce procura remediar os critérios de clareza e distinção acrescentando um terceiro, o dos efeitos práticos e sensíveis que se podem esperar das idéias: "Se a tarefa proposta por Descartes era fornecer um Discurso do método de conduzir o raciocínio corretamente e de buscar a verdade nas ciências, o que Peirce se propunha não era muito distinto. Tal como Descartes, ele reconhecia a necessidade de um método para se chegar a crenças confiáveis" (p. 62). Por sinal, Santaella comenta o escopo da denominação anticartesiano de seu próprio livro: "um título, aliás, que alguns poderiam preferir substituir por acartesiano ou não-cartesiano" (p. 24). Acrescente-se também a denominaçãopós-cartesiano, porque, na medida em que Descartes representa a modernidade, Peirce, que veio a falecer pouco antes da Primeira Guerra, encontrava-se atravessando o umbral do mundo pós-moderno.

Retomando a argumentação, Santaella, após limpar o terreno no que tange ao conceito cartesiano de intuição, passa a reconstruir o sistema peirceano. A palavra reconstruir, aqui utilizada, fornece uma boa dimensão do trabalho produzido. O fato é que a autora discorre sobre a evolução das idéias de Peirce não somente tendo em vista seu trajeto cronológico, mas também considerando o destino final dessas idéias, a saber, 
a concepção de uma ampla lógica do conhecimento, que significa, no final das contas, um método semiótico. Para ilustrar isso, é conveniente fazer uma citação direta que sumariza esse ponto:

[Peirce] chamava a lógica de arte de conceber métodos de pesquisa, considerando-a "método dos métodos" (CP 7.59). Afirmava também que a produção de um método para a descoberta de métodos era um dos principais problemas da lógica (CP 3.364). Não é por acidente que toda a obra peirceana pode ser interpretada como uma tentativa de criar uma teoria dos métodos capaz de impulsionar o avanço das ciências. Ele previa que, alargada numa concepção vasta e generosa a qual, mais para o fim da vida, iria tomar como sinônimo de semiótica, a lógica, como senhora das ciências, haveria de encontrar seu tempo (p. 7०-9).

Essa concepção de lógica ampliada pode gerar certas dificuldades quando estudamos Peirce pela primeira vez. Por exemplo, o conceito de inferência utilizado por ele não se resume à noção de inferência dedutivamente válida da lógica formal. Para Peirce, inferências indutivas e abdutivas, embora não transportem necessariamente a verdade das premissas para a conclusão, são também importantes, desde que pelo menos conduzam mais vezes à verdade do que à falsidade. Por exemplo, se determinada inferência leva à verdade em 70\% dos casos, para o cientista isso já é algo que tem seu valor. Isso é particularmente importante para se entender como a abdução peirceana substitui o papel da intuição cartesiana e, por conseguinte, como isso leva ao falibilismo da teoria peirceana.

Sucintamente, é um equívoco imaginar que o ponto de partida de uma cadeia de inferências deve ser uma idéia clara e distinta intuitivamente percebida como tal; para Peirce, partimos de certas apostas racionais ou, por assim dizer, "chutes" estimados, aos quais o filósofo deu o nome de abduções. Para ilustrar o que são, tome-se o seguinte exemplo, fornecido por Peirce no ensaio "Deduction, induction and hypothesis" (1992). Suponhamos que estamos em uma sala onde há várias sacas de feijão, cada uma delas com diferentes proporções de feijões brancos e pretos. Imaginemos também que sobre uma mesa há uma amostra, um punhado de feijões, com determinada proporção, digamos três feijões pretos para cada branco. Investigamos, então, todas as sacas e encontramos uma onde ocorre a mesma proporção da amostra que estava na mesa. Ficamos, pois, inclinados a dizer que a amostra deve ter vindo daquela saca particular, isto é, que a "causa" da proporção encontrada na amostra é o fato dela ser oriunda de uma determinada saca. O que estamos fazendo é abduzir, ou aventar uma hipótese que, se não é de antemão comprovadamente correta, ao menos tem uma grande possibilidade de assim o ser. 
O ponto de alavancagem dessa operação lógica coloca-se na suposição de que nós, humanos, fazemos abduções instintivamente; isto é, para Peirce, a mente humana evoluiu no interior das leis do universo, de modo que a mente "incorpora tais leis em sua própria estrutura instintiva [...]. Uma mente adaptativa com uma disposição apropriada possui uma luz natural, a luz da natureza, ou seja, a faculdade de percepção abdutiva da generalidade real" (Santaella, 2004, p. 106). Que fique claro, entretanto, que tal luz natural instintiva não garante inequivocamente a verdade das hipóteses aventadas - daí o falibilismo -, ela somente nos inclina em direção à verdade. Todavia uma investigação diligente precisa de passos subseqüentes.

E quais são esses passos subseqüentes da investigação? De acordo com Santaella, "tendo as hipóteses sido construídas e selecionadas no estágio abdutivo, elas devem passar, a seguir, pelo processo de verificação, o qual tem, por sua vez, dois estágios: a dedução e a indução" (p. 153). O estágio de dedução consiste em levantar as conseqüências experimentais das hipóteses assumidas. Leitores familiarizados com a obra de Karl Popper já devem estar percebendo as afinidades entre as visões dele e de Peirce, pois, até agora, trata-se da constituição de um método experimental hipotético-dedutivo. Entretanto, para Peirce, não somente podemos descartar hipóteses via modus tollens, como também podemos encaminhar uma verificação "positiva" por meio de um alargamento da experiência, procurando extrapolar em direção ao longo termo, o que nos aproximaria, no limite, à efetiva realidade do objeto de estudo. Nas palavras de Santaella:

Uma inferência baseada em um número limitado de exemplos pode muito bem estar errada, mas quando a amostragem testada é alargada, a razão começa a se aproximar da verdade [...]. Essa espécie de convergência para a verdade é atingida pelo método de prolongamento da experiência, quer dizer, o método que exige que a ciência nunca deixe de continuar (p. 157).

Essa continuada expansão das experiências em direção ao longo termo, por meio do acréscimo de amostragens justas, tomadas aleatoriamente, com intuito de reforçar ou enfraquecer a hipótese e suas conseqüências deduzidas, é o que Peirce entende por estágio indutivo. Isso significa, diz Santaella, "se certificar acerca de quão longe as conseqüências estão de acordo com a experiência, e julgar se a hipótese está sensivelmente correta, ou se requer uma modificação inessencial, ou se deve ser inteiramente rejeitada" (p. 158). O método proposto por Peirce pode ser considerado como uma espécie de encadeamento metodológico hipotético-dedutivo-indutivo, não havendo privilégio ou parcialidade em relação a nenhum dos estágios. Portanto, o pragmatismo clássico envolve pluralismo metodológico; e isso de jeito nenhum significa uma guinada 
antimetodológica. Em resumo, nas palavras de Peirce: "Abdução é o processo de formação de uma hipótese explanatória. É a única operação lógica que apresenta uma idéia nova, pois a indução nada faz além de determinar um valor, e a dedução meramente desenvolve as conseqüências necessárias de uma hipótese pura" (Peirce, 2000, p. 220).

O estudo de Santaella ganha seu caráter mais semiótico nos capítulos finais. Discute-se então o que é o método semiótico - a saber, uma lógica ampliada e generosa - bem como se discorre sobre o que a semiótica não é. O ponto de destaque é a contraposição entre as abordagens logicistas e as psicologistas nesse campo. Santaella bem enfatiza que Peirce procurava uma relação equilibrada entre essas duas perspectivas; entretanto, por certas razões históricas, há entre os comentadores uma tendência na direção da psicologização. A autora então empreende uma crítica dessa concepção, sublinhando o quanto a semiótica se encontra ligada a uma visão objetiva do conhecimento.

Neste ínterim, aparecem algumas observações que ultrapassam o escopo da retificação dos conceitos, passando a ocorrer uma espécie de reprovação da psicologia em geral. Por exemplo, em certa passagem Santaella comenta que "não é de se estranhar que tanto [Charles] Morris quanto os psicólogos pragmatistas tenham encontrado todo o sucesso que faltou a Peirce. A psicologia é, para o ser humano, o que o sorvete é para a criança. Nela ele se lambuza e, não satisfeito, lambe os dedos" (p. 178). Bem, colocações dessa natureza não ajudam ao debate; ao menos por duas razões, uma de ordem mais conceitual e outra de cunho histórico.

Do ponto de vista conceitual é preciso perceber que aquilo que chamamos de psicologia é uma área muito pouco uniforme. Na verdade, devemos também considerar os psicólogos como uma população de pesquisadores, cada qual nutrindo seus pontos de vista. Há psicólogos que acabam psicologizando tudo o que investigam; mas há outros que reconhecem os limites do psicologismo. Por exemplo, a chamada Psicologia da Gestalt baseia-se em uma perspectiva formalista da mente humana, podendo ser considerada uma topologia do psíquico. Nessa abordagem, a noção de "forma" pode ensejar uma espécie de matemática qualitativa das relações entre percepção, ação e cognição, uma coisa que Peirce muito provavelmente aprovaria; por exemplo, o filósofo sublinhava a importância da lei de Fechner, que relaciona os estímulos exteriores às dinâmicas neuronais por meio de uma função logarítmica. Uma crítica indiscriminada à psicologia acaba, indiretamente, enfraquecendo àqueles que poderiam ajudar nessa objetivação do mental. Metaforicamente, tais críticas são como "fogo-amigo", causando baixas em fileiras que se ocupam em desenvolver o lado objetivo da psicologia.

Além disso, há um detalhe de natureza factual que precisa ser examinado. A denominação "psicólogos pragmatistas" remete inevitavelmente à figura de William James. Pergunta-se, James psicologizou o pragmatismo? A resposta é evidentemente 
que sim. Mas, pode-se cogitar que, caso James não escorregasse nesse ponto, provavelmente o próprio Peirce não teria se dedicado tanto ao refinamento de suas idéias. Trata-se de um daqueles aparentes deslizes cujo resultado foi, no final das contas, um estímulo aos desenvolvimentos subseqüentes.

O fato é que a sina de Peirce foi ter como seu maior e mais próximo interlocutor o psicólogo pragmatista James; e vice-versa, pois Peirce também, em certas ocasiões, foi um crítico feroz de James. E tais confrontações parecem tê-los feito apurar cada vez mais suas concepções. Prova documental disso são as inúmeras cartas trocadas entre eles durante toda a vida. Aliás, Santaella utiliza passagens dessas cartas para mostrar a evolução das idéias peirceanas, e um dos pontos mais acertados do livro é o último capítulo, intitulado "Palavras finais", uma tradução de uma carta de Peirce a James, na qual o primeiro faz um apanhado geral de suas realizações. Nota-se a grande intimidade entre eles, a despeito de suas divergências. Fica, assim, uma certa sensação de dissonância entre a reprovação generalizada aos psicólogos pragmatistas e a posterior utilização de uma carta endereçada ao maior dos psicólogos pragmatistas. O chamado rapto (kidnaping) das idéias de Peirce feito por James é fato consumado, como também o é que James obteve muito mais sucesso em vida do que Peirce. Não obstante, o psicólogo já era famoso antes de se filiar publicamente ao pragmatismo - o que ocorreu apenas em 1898, por ocasião da conferência "Philosophical conceptions and practical results" (James, 1992 [1898]) - e, como é bem sabido, utilizara essa popularidade para promover os trabalhos originais de Peirce. É conveniente evitar o repisar de disputas fraternais já superadas pelos próprios fundadores do pragmatismo.

No mais, Santaella é praticamente leitura obrigatória para estudantes do pragmatismo no Brasil e, como já dito anteriormente, também tem sua utilidade para integrantes de outros círculos intelectuais, tais como filósofos da ciência em geral. Isso porque o pragmatismo apresentado, recheado de "duros" componentes semióticos, retifica a concepção de que tal método filosófico consiste em uma mera desconstrução do método científico. Se o leitor deseja se ver livre de clichês que colocam o pragmatismo, erroneamente, como um mero antimétodo, $O$ método anticartesiano de C. S Peirce é recomendável. É anticartesiano, mas é método.

Renato Rodrigues Kinoughi

Pesquisador do Projeto Temático "Estudos de filosofia e história da ciência" da FAPESP, pós-doutorando do Departamento de Filosofia da Universidade de São Paulo. 


\section{REFERÊNGIAS BIBLIOGRÁFICAS}

Descartes, R. Meditações. In: Lebrun, G. (Org.). Descartes. Trad. de E. Corvisieri. São Paulo, Nova Cultural, 1999 [1641]. p. 233-334. (Os Pensadores).

James, W. Philosophical conceptions and practical results. In: Myers, G. E. (Org.). William James Writings 1878-1899. Nova Iorque, Literary Classics of the United States, 1992 [1898]. p. 1077-97.

Lebrun, G. (Org.). Descartes. Trad. de E. Corvisieri. São Paulo, Nova Cultural, 1999. (Os Pensadores).

Myers, G. E. (Org.). William James Writings 1878-1899. Nova Iorque, Literary Classics of the United States, 1992.

Peirce, C. S. The collected papers of Charles Sanders Peirce. Ed. de C. Hartshorne; P. Weiss \& A. W. Burks. Cambridge, Harvard University Press, 1931-1958. 8 v. (CP).

.The essential Peirce: selected philosophical works. Ed. de N. Houser et al. Bloomington, Indiana University Press, 1992. 2 v.

. Semiótica. Trad. de J. T. Coelho Neto. São Paulo, Perspectiva, 200o. (Coleção Estudos, 46). 